\title{
Editorials
}

\section{Pharmacovigilance on the turn?}

\author{
Adverse reactions methods in 2012
}

\section{PATIENTS TOO SHOULD REPORT SUSPECTED ADVERSE DRUG REACTIONS}

On 31 December 2011 a new European Directive on pharmacovigilance ${ }^{1}$ signalled a very important change. It amended Directive 2001/83/EC on the community code relating to human medicines, and said that Union rules on pharmacovigilance:

should be based on the crucial role of healthcare professionals in monitoring the safety of medicines, and should take account of the fact that patients are also well placed to report suspected adverse reactions to medical products. It is therefore appropriate to facilitate the reporting of suspected adverse reactions by both healthcare professionals and patients, and to make methods for such reporting available to them."

Views in the pharmacovigilance community had been divided, many for various reasons doubting the value or practicality of patient reporting. Some countries had used it early, such as the US, Denmark, the Netherlands, and the UK; others had rejected it, such as Germany, France, and Switzerland. Member States should implement the Directive by 21 July 2012.

In 2010 and 2011 two comprehensive reviews appeared, funded by the EU Executive Agency for Health \& Consumers ${ }^{2}$ and the UK National Institute of Health Research. ${ }^{3}$

They concluded that direct reports from patients can add value to pharmacovigilance: these are uninfluenced by the prescriber's interpretation; they give more detail, often with useful information on causality; and many explicitly mention the effects on the person's life, family, and carers. Patients also report different drugs and types of reactions than professionals do. Patient reporting helps the community in that it makes patients active participants and can improve health literacy. Furthermore, their reports describe the burden of adverse drug reactions on individuals, which current pharmacovigilance systems miss.

\section{SPOTTING ADVERSE DRUG REACTIONS PROMPTLY}

New adverse drug reactions often first come to light in isolated well-documented incidents ${ }^{4,5}$ not in clinical trials. Even data

"It is ... appropriate to facilitate the reporting of suspected adverse reactions by both healthcare professionals and patients, and to make methods for such reporting available to them.

on harms gathered in clinical studies are often not reported at all or in a potentially misleading way (for example, using $95 \%$ confidence intervals). Studies are often too small to allow for a reasonable assessment of harm.

It will take time for patient reporting to be properly incorporated into pharmacovigilance practice, especially in regulatory agencies and pharmaceutical companies; they focus largely on statistical and epidemiological methods and rarely consider narrative or qualitative data. But the World Health Organization has just published short practical guidelines on how to set up national systems for the general public to report adverse reactions to medicines; ${ }^{6}$ they deserve enthusiastic implementation.

\section{HARMS ARE NEGLECTED IN RESEARCH}

The huge imbalance between the ways in which benefits and harms are studied means that harms are under-ascertained, under-recorded, poorly investigated, and poorly understood, and that their recognition may be long delayed. The neglect of harms is partly due to what has been called the 'Conspiracy of Goodwill':

the fervent wish of all parties (health professionals, government, manufacturers and users) that drugs should be safe and effective, and never anything less."

Harms are often unrecognised, ignored,

\section{REFERENCES}

. Directive 2010/84/EU of the European Parliament and of the Council. Official Journal of the European Union 2011; 53: L348/74.

2. Herxheimer A, Crombag R, Alves TL. Direct Patient Reporting of adverse dug reactions a fifteen-country survey and literature review: a briefing paper. Netherlands: Health Action International, 2010. http://haieurope.org/wpcontent/uploads/2010/12/10-May-2010Report-Direct-patient-reporting-of-adversedrug-reactions.pdf (accessed 9 Jul 2012).

3. Avery AJ, Anderson C, Bond CM, et al. Evaluation of patient reporting of adverse drug reactions to the UK Yellow Card Scheme: literature review, descriptive and qualitative analyses, and questionnaire surveys. Health Technol Assess 2011; 15(20): 1-234, iii-iv.

4. Aronson JK. Unity from diversity: the evidential use of anecdotal reports of adverse drug reactions and interactions. J Eval Clin Pract 2005; 11(2): 195-208.

5. Vandenbroucke J. Observational research, randomised trials and two views of medical science. PLoS Med 2008; 5(3): e67.

6. World Health Organization. Safety monitoring of medicinal products: reporting system for the general public. Geneva: WHO, 2012.

7. Medawar C, Hardon A. Medicines out of control? Amsterdam: Aksant, 2004.

8. Loke YK, Price D, Derry S, Aronson JK. Case reports of suspected adverse drug reactions - systematic literature survey of follow-up. BMJ 2006; 332(7537): 335-339.

9. Chandler P, Herxheimer A. Unexpected aggressive behaviour: interaction of bupropion and alcohol. Int J Risk Saf Med 2011; 23(3): 133-137. [Nov] DOI 10.3233/JRS-2011-0533.

\section{"The huge imbalance between the ways in which benefits and harms are studied means that harms are under-ascertained, under-recorded, poorly investigated, and poorly understood, and that their recognition may be long delayed.}


denied, hidden, or attributed to other causes. Thorough analyses require detailed descriptions, but regulators and companies have made few efforts to elicit them. Few reports are followed up; ${ }^{8}$ reporters get an impersonal acknowledgement but no feedback. Regulators and companies resist disclosing even the details they have obtained; usually citing data protection and/or commercial confidentiality. The protection of public health and patients should always come first.

\section{CONCLUSION}

Patients inclined to blame a doctor for a suspected adverse effect may not do so openly, but doctors could encourage and help patients to report it. 'Joint reports (for example Chandler and Herxheimer ${ }^{9}$ ) might give added value, [re?]build trust, and improve public understanding of medicines.

\section{Andrew Herxheimer,}

Co-Convenor, Cochrane Adverse Effects Methods Group; Emeritus fellow, UK Cochrane Centre, Oxford.

\section{ADDRESS FOR CORRESPONDENCE}

\section{Andrew Herxheimer}

9 Park Crescent, London, N3 2NL, UK.

E-mail: a.herxheimerantlworld.com

\section{Competing interests}

The author has declared no competing interests.

DOI: 10.3399/bjgp12X653453 